\title{
The peroneocalcaneus internus tendon: case report of a rare cause of posterior ankle impingement treated by arthroscopy
}

\author{
Liselore Maeckelbergh $^{1 *}$, Giovanni Matricali ${ }^{1-3}$ and Sander Wuite ${ }^{1,3}$ \\ ${ }^{1}$ University Hospitals Leuven, Department of orthopaedic surgery, Weligerveld 1, 3212 Pellenberg, Belgium \\ ${ }^{2} \mathrm{KU}$ Leuven, Department of Development and regeneration, Belgium \\ ${ }^{3} \mathrm{KU}$ Leuven, Institute of Orthopaedic Research and Training, Belgium
}

\begin{abstract}
Posterior impingement is often associated with an os trigonum or enlarged posterior process of the talus. Other causative factors include soft-tissue impingement by the flexor hallucis longus, a hypertrophic capsule, calcified inflammatory tissue, gouty os trigonum, soft-tissue impingement and the posterior intermalleolar ligament. In our case report, we present a 20-year-old hurdler with clinical signs of posterior impingement and on Magnetic resonance imaging (MRI) signs of posterior impingement with limited fluid distension of FHL sheath and a prominent posterior process. At the posterior ankle arthroscopy, inspection of the flexor hallucis longus showed an impingement of this tendon in its tunnel by a peroneocalcaneus internus tendon. The peroneocalcaneus internus tendon was resected freeing the flexor hallucis longus in his tunnel. 4 months after surgery the patient returned to his sport activities without complaints. .
\end{abstract}

\section{Case report}

A 20-year-old man, a semiprofessional hurdler, presented on the outpatient clinic with a six months history of pain posterior in the left ankle during sport activities. On physical examination there was pain palpating the posterior ankle joint and around the flexor hallucis longus (FHL) region posteromedial in the ankle during active flexion of the hallux. There was deep pain on the posterior process of the talus with a positive forced plantarflexion posterior impingement test. Magnetic resonance imaging (MRI) showed signs of posterior impingement with limited fluid distension of FHL sheath and a prominent posterior process. SPECT CT showed an increased uptake in the posterior process of the talus. Because of his complaints and high demanding level of sport activities an arthroscopic partial resection of the posterior process was suggested with a release of the FHL. The posterior arthroscopy was performed with the two posterior portals technique described by van Dijk [1]. The presumed FHL was located and the prominence of posterior process of the talus revealed. After resection of the prominence we noticed that the presumed FHL was not moving by flexion and extension of the hallux, but moved just with the mobilisation of the calcaneus. After careful inspection of the tendon, a second tendon anterior to the forementioned tendon was revealed. This tendon prooved to be the FHL, when the hallux was flexed and extended. The anatomically more posterior tendon appeared to be an accessory tendon (Figures 1 and 2). With mobilization of the hallux, there was no movement of this tendon, it only moved when the calcaneum was mobilised. We presumed that it was the peroneocalcaneus internus (PCI) tendon. An accessory posteromedial portal was made to perform a resection with the punch, scissor and shaver, because of the interference with the FHL in his tunnel (Figure 3). After this procedure the FHL could run freely in the tunnel without a sign of impingement. Postoperatively the pain was resolved. The Foot

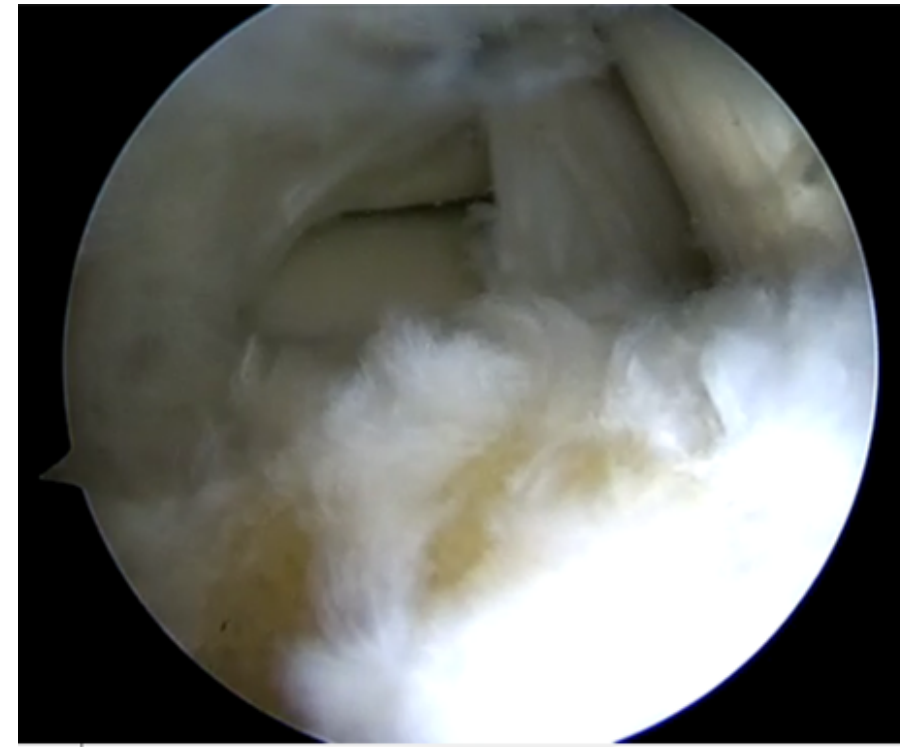

Figure 1. Posterior view ankle after resection of the posterior facet of the talus

${ }^{\star}$ Correspondence to: Liselore Maeckelbergh, University Hospitals Leuven, Department of orthopaedic surgery, Weligerveld 1, 3212 Pellenberg, Belgium, E-mail: liselore.maeckelbergh@hotmail.com

Key words: posterior arthroscopy, ankle, accessory muscle, posterior ankle impingement, flexor hallucis longus

Received: March 04, 2018; Accepted: March 27, 2018; Published: March 29, 2018 


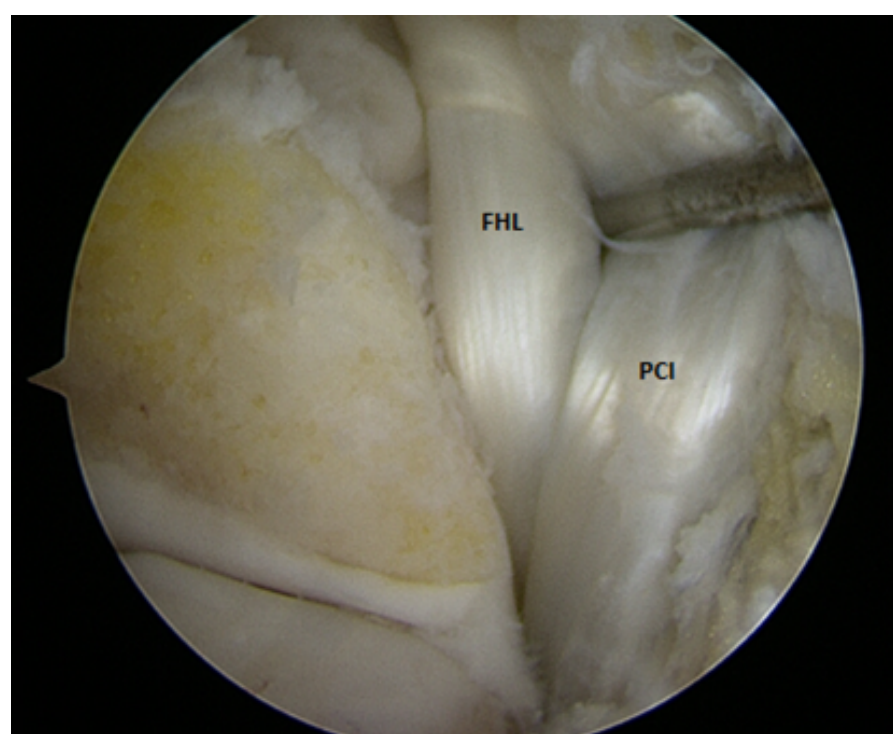

Figure 2. Posterior view of the ankle region after resection of the posterior facet, FHL and PCI tendon

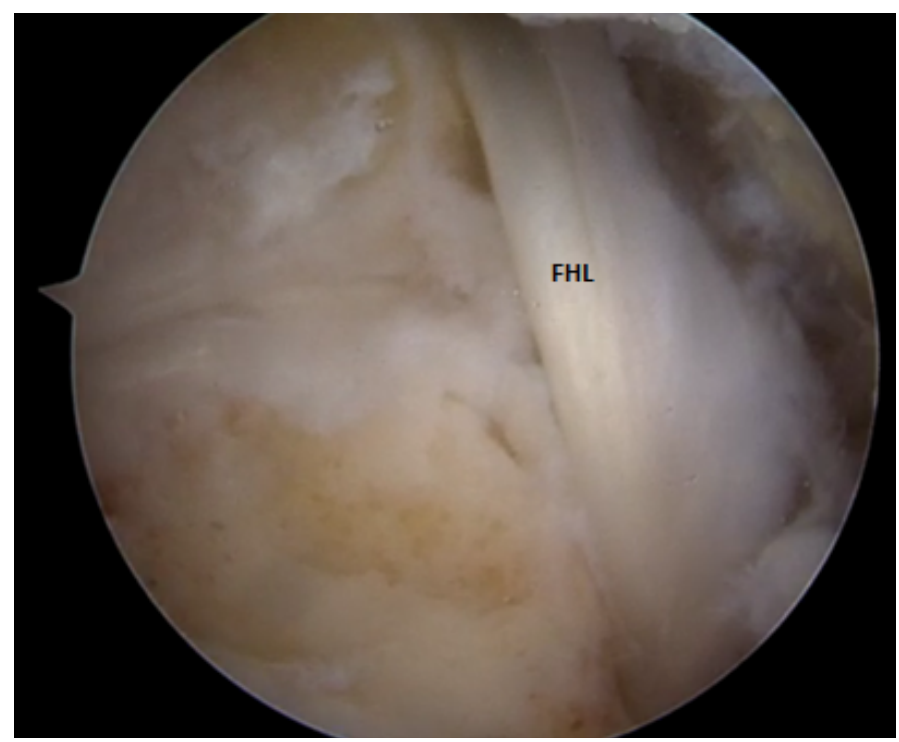

Figure 3. Posterior view of the ankle region after resection of the PCI

and Ankle Disability Index (FADI) showed a score of 97.1 (maximum 100) 2 months and a score of 994 months postoperatively. He returned to his sport activities 4 months after the operation. 6 months after the operation he had no complaints.

\section{Discussion}

In this case we arthroscopically found an accessory tendon next to the FHL, the peroneocalcaneus internus, causing posterior impingement that was resolved by resecting the PCI tendon.

Posterior impingement is mostly described in association with an os trigonum or enlarged posterior process of the talus. Other causative factors include a hypertrophic capsule, calcified inflammatory tissue, gouty os trigonum, soft-tissue impingement and the posterior intermalleolar ligament.

The normal structures of the medial ankle include from anterior to posterior the tibialis posterior, flexor digitorum longus, tibial neurovascular bundle (posterior tibial artery and vein, tibial nerve) and flexor hallucis longus.

Reports in the literature have described an array of accessory muscles in the ankle [2-5]. The majority of these muscles have been found incidentally, either during imaging or surgery. The pathology is often missed or misdiagnosed. Although often asymptomatic, the patients may present with symptoms like pain, a mass, compressive neuropathy, compartment syndrome and hind-foot deformities.

The five accessory muscles described to be found within the tarsal tunnel are the flexor digitorum accessorius longus (FDAL), peroneocalcaneus internus, accessory soleus, peroneus quartus, and tibiocalcaneus internus. The FDAL is the most common medial accessory muscle $(6 \%)[2,5]$.

The peroneocalcaneus internus is relatively rare (1\% prevalence). It often presents bilaterally (75\%). It arises from the medial aspect of the lower half of the fibula distal to the origin of the flexor hallucis longus muscle and it runs inferomedially just lateral and posterior to the tendon of the FHL, to insert into the distal segment of the medial calcaneal surface inferior to the sustentaculum tali or into the sustentaculum tali itself. Benjjani described that the muscle is bordered medially by the FHL and its tendon, laterally by the fascia that separates it form the peroneal muscles and posteriorly by the soleus. It is bordered posteriorly by the tibiotalair joint, the interosseous ligament and the tibia [5].

Meckel was the first to describe this muscle in 1815 and it is further described by Macalister in 1872. Perkins described the actions of the muscle as assisting in plantar flexion of the foot at the ankle joint and its limited function in supination or inversion of the foot $[1,6,7]$.

Because of the proximity to the neurovascular bundle in the tarsal tunnel, this muscle has been implicated a cause of tarsal tunnel syndrome, but is uncommon. The FDAL tends to be present more frequently with tarsal tunnel syndrome [8-10].

The FHL is used as the most important landmark for posterior hindfoot endoscopy $[1,10,11]$. It runs in the groove between the posteromedial and posterolateral tubercles of the talus. It serves as a medial boundary by protecting the posteromedial neurovascular bundles situated anteromedial and superficial of the FHL. The presence of the PCI poses a risk of tibial nerve or vessel injury. This tendon runs posteriorly of the FHL in the plane superficial to the neurovascular bundle. So the PCI can be misidentified as the FHL and the approach can be altered [8]. The tibial neurovascular bundle is situated more anteromedial with respect to the PCI than the FHL.

Mellado et al. studied $100 \mathrm{MRI}$ scans in an asymptomatic population. This revealed one PCI. Three patients in his patient population had a MRI scan for a painfull ankle and were noted to have a PCI [6].

Seipel presented a 14-year old boy with ankle pain. MRI showed the presence of a PCI [9]. After failure of a conservative treatment, an open resection was performed with excellent result. Phisitkul described two cases where the PCI was found during arthroscopy. No further treatment was done to this tendon with good result [8]. Duran-Stanton reported a case of tarsal tunnel syndrome in presence of a PCI [3]. Conservative treatment (physiotherapy, NSAID and soft shoe) gave a good result. Howe reported a 68-year-old gentleman with acute on chronic ankle pain. MRI showed an accessory muscle between the FHL and peroneus brevis (PB). The patient was diagnosed with instability and degenerative joint disease and was treated conservatively [4]. 


\section{Conclusion}

The peroneocalcaneus internus muscle is a rare accessory muscle of the medial ankle. Knowledge of this muscle is important to help differentiate it from the FHL. Especially in cases where hindfoot arthroscopy may be considered, it is important to not misidentify this muscle.

Our case presented a young athlete with posterior impingement of the ankle. MRI did not reveal an accessory muscle. During arthroscopy we performed a resection of the prominent posterior process of the talus and a resection of the PCI with a good result 3 months after the operation. He returned to normal sport activities after 4 months. In literature, a few case reports are available and all started with a conservative therapy. If the symptoms did not resolve an open or arthroscopic resection was performed with good results.

\section{References}

1. Allegra F, Maffuli N (2010) Double posteromedial portals for posterior ankle arthroscopy in supine position. Clin Orthop Relat Res 468: 996-1001. [Crossref]

2. Bejjani FJ, Jahss MH (1985) Le Double's study of muscle variations of the human body. Part I: Muscle variations of the leg. Foot Ankle 6: 111-134. [Crossref]
3. Duran-Stanton AM, Bui-Mansfield LT (2010) Magnetic Resonance Diagnosis of Tarsal Tunnel Syndrome Due to Flexor Digitorum Accessorius Longus and Peroneocalcaneus Internus Muscles. J Comput Assist Tomogr 34: 270-2. [Crossref]

4. Howe BM, Murthy NS (2012) An accessory peroneocalcaneus internus musle with MRI and US correlation. $J$ Radiol Case Rep 6: 20-25. [Crossref]

5. Lambert HW, Atsas S, Fox JN (2011) The fibulocalcaneus (peroneocalcaneus) internus muscle of MacAlister: Clinical and surgical implications. Clin Anat 24: 1000-4. [Crossref]

6. Mellado JM, Rosenberg ZS, Beltran J, Colon E (1997) The peroneocalcaneus internus muscle: MR imaging features. AJR Am J Roentgenol 169: 585-588. [Crossref]

7. Perkins JD (1914) An anomalous muscle of the leg: Peronaeocalcaneus internus. The Anatomical Record 8: 21-25.

8. Phisitkul P, Amendola A (2010) False FHL: a normal variant posing risks in posterior hindfoot endoscopy. Arthroscopy 26: 714-8. [Crossref]

9. Seipel R, Linklater J, Pitsis G, Sullivan M (2005) The peroneocalcaneus internus muscle: an unusual cause of posterior ankle impingement. Foot Ankle Int 26: 890-893. [Crossref]

10. Sim JA, Lee BK, Kwak JH (2006) New posteromedial portal for ankle arthroscopy. Arthroscopy 22: 799. [Crossref]

11. Niek van Dijk C (2006) Anterior and posterior ankle impingement. Foot Ankle Clin 11: 663-683. [Crossref]

Copyright: (C)2018 Maeckelbergh L. This is an open-access article distributed under the terms of the Creative Commons Attribution License, which permits unrestricted use, distribution, and reproduction in any medium, provided the original author and source are credited. 